\title{
STUDY OF AETIOLOGY AND CLINICAL OUTCOMES IN COMA PATIENTS WITH NORMAL BRAIN CT SCAN
}

Wuppala Santha Raja Ratnam¹, Malladi Srinivasa Rao ${ }^{2}$

${ }_{1}^{1}$ Assistant Professor, Department of Medicine, Andhra Medical College, Vishakapatnam, Andhra Pradesh, India.

2Professor, Department of Cardiology, Andhra Medical College, Vishakapatnam, Andhra Pradesh, India.

\section{BACKGROUND}

ABSTRACT

Coma is one of the common problems with which patients get admitted into the emergency department. Coma is a state of unconsciousness from which the patient cannot be awakened; it indicates either structural or functional abnormalities in the reticular activating system. In a significant number of cases CT scan can be normal if the coma is due to toxic or infections or metabolic abnormalities.

Aim: The present study was undertaken to study the profile of coma patients with normal CT scan brain with respect to aetiology, coma scale and prognosis.

\section{MATERIALS AND METHODS}

It is a prospective observational study. 120 cases of coma patients with normal CT Brain admitted into the acute medical care unit, King George Hospital, Visakhapatnam were studied (from October 2006 to October 2008).

\section{RESULTS}

Of the 120 patients, males (57.5\%) were found to be more common. Toxic causes (of which alcohol intoxication) and infectious aetiology (of which cerebral malaria) accounted for $75 \%$ of cases. Glasgow coma scale and duration of coma with respect to the prognosis were studied.

\section{CONCLUSION}

Coma with normal CT scan brain was more common in males. Majority of cases were due to toxic or infectious causes and metabolic causes are other common causes. Increased mortality was noted in uraemic encephalopathy, advanced age group, Glasgow coma scale 5 or less or duration of coma is more.

\section{KEY WORDS}

Coma, CT Scan, Reticular Activating System, Metabolic Causes, Glasgow Coma Scale.

HOW TO CITE THIS ARTICLE: Ratnam WSR, Rao MS. Study of aetiology and clinical outcomes in coma patients with normal brain CT scan. J. Evolution Med. Dent. Sci. 2018;7(28):3234-3237, DOI: 10.14260/jemds/2018/727

\section{BACKGROUND}

Coma is one of the common neurological problems encountered in the emergency department. Since it implies severe central nervous system dysfunction, there is need to evaluate it quickly and thoroughly to protect brain against serious irreversible damage. Coma is a state of unconsciousness in which a person cannot be awakened; fails to respond normally to painful stimuli, light or sound; lacks a normal wake-sleep cycle; and does not initiate voluntary actions. ${ }^{1}$ Consciousness is the condition of normal awake individual, of which the content of consciousness is determined by cerebral hemispheres and the thalamus and the state of consciousness is determined by the ascending reticular activating system in the brainstem, both structural or functional of the structures produce coma. ${ }^{2}$ Despite the best treatment, only $15 \%$ of patients with unconsciousness from no traumatic causes make recovery. ${ }^{3}$ Glasgow Coma Scale is a very popular and integral part of management of coma patients, which is used to assess the severity of coma.

'Financial or Other Competing Interest': None.

Submission 18-05-2018, Peer Review 23-06-2018,

Acceptance 01-07-2018, Published 09-07-2018.

Corresponding Author:

Dr. Wuppala Santha Raja Ratnam,

Flat No. 210, Vasavi Paradise NAD Kotha Road,

Gowri Nagar, Vishakapatnam-530009, Andhra Pradesh, India.

E-mail: sakaprasad@gmail.com

DOI: $10.14260 /$ jemds $/ 2018 / 727$

\section{(c) $(1)$}

The scale was described in 1974 by Graham Teasdale and Bryan Jennett as a way to communicate about the level of consciousness of patients with an acute brain injury. 4

\section{Glasgow Coma Scale \\ GCS score $=\mathrm{E}+\mathrm{M}+\mathrm{V}$.}

\section{Eye Opening Scores}

- 4: Spontaneously.

- 3: To verbal command.

- 2: To pain.

- 1: No response.

\section{Best Motor Response Scores}

- 6: Obeys command.

- 5: Localises pain.

- 4: Flexion withdrawal.

- 3: Flexion abnormal (Decorticate).

- 2: Extension (Decerebrate).

- 1: No response.

Best Verbal Response Scores

- 5: Oriented and converses.

- 4: Disoriented and converses.

- 3: Inappropriate words; cries.

- $\quad$ 2: Incomprehensible sounds. 
- 1 : No response.

- $\quad$ Mild: 13 - 15 points.

- Moderate: 9 - 12 points.

- Severe: 3 - 8 points. Coma patients have scores less than 8.

Coma is produced by one of the two Broad Groups of Problems

1. Structural abnormalities of upper brain stem and lower diencephalon or more widespread changes in both cerebral hemispheres.

2. Non-structural, sub-microscopic changes secondary to metabolic abnormalities, toxic or infectious causes.

The former group is associated with abnormalities in imaging like CT scan, whereas in the second group gross structural imaging like CT scan brain. Coma secondary to non-structural causes constitutes an important cause of coma accounting for majority of cases. ${ }^{5}$ In a study by 0 Keefe et al in patients with altered mental status, non-structural causes accounted for $65 \%$ and structural causes $33 \%$ and psychiatric cause in $2 \%$. In the study by Plum and Posner of 500 patients of $326(65 \%)$ were because of metabolic and other diffuse disorders.

The Characteristics of Coma Patients with Normal CT Scan Brain when compared to those with Structural Abnormality-

1. Confusion and stupor commonly precede motor signs.

2. Motor signs are usually symmetrical.

3. Pupillary reactions are preserved, except in specific poisons altering pupils.

4. Asterixis, myoclonus, tremor and seizures are common.

5. Acid base imbalance, hyper or hypoventilation is frequent.

6. Asymmetric ocular movements are uncommon, if present indicate structural causes.

7. Muscle tone is usually symmetric and normal or decreased in metabolic coma, whereas asymmetrical tone is seen in structural causes.

\section{Aim}

To study the aetiology and clinical profile, outcome and the prognostic factors of patients admitted with coma, with normal CT scan brain, attending the emergency department in King George Hospital, Visakhapatnam.

\section{MATERIALS AND METHODS}

It is a prospective observational study, 120 cases of coma patients with normal CT Brain admitted into the acute medical care unit, King George Hospital, Visakhapatnam were studied (from October 2006 to October 2008).

\section{Inclusion Criteria}

1. Patients presenting with loss of consciousness of more than 6 hours duration.

2. Glasgow coma scale $<8$ at admission.

3. Normal CT scan brain.

\section{Criteria for Normal CT Scan Brain are-}

- Cerebral parenchyma should show normal grey and white matter differentiation and there should be no space occupying lesion.
- Posterior fossa and fourth ventricle should be normal in size and structure.

- Ventricular system and cisterns should be normal in size and pattern.

- No extra axial collection of blood, fluid.

- Skull vault and soft tissues should appear normal.

\section{Exclusion Criteria}

1. Patients with head injury.

2. Abnormal CT scan brain.

3. Patients with stroke (CVA).

A detailed history was taken and evaluation was done to identify the cause of coma. Level of consciousness is defined by Glasgow coma scale. CT scan was done in all these patients. Investigations like complete blood counts, ESR, renal function tests like serum creatinine, blood urea, liver function tests and serum electrolytes were done. Patients were followed till their recovery, discharge from the hospital or death. The outcome was recorded as survived or dead. Among the survivors it was further graded as good recovery, moderate disability or severe disability or persistent vegetative state.

\section{Good Recovery}

Patients who regained the ability to conduct a normal life or if a pre-existing debility exists, to resume the previous level of activity.

\section{Moderate Disability}

Patients who achieve independence in activities of daily living, but retain physical or mental limitations that preclude them to resume previous level of function.

\section{Severe Disability}

Patients who regained some cognitive function, but depend on others for daily support.

\section{Vegetative State}

Patients who are awaken, but give no signs of cognitive awareness.

\section{No Recovery}

Patients who remain in coma till death.

\section{Statistical Analysis}

Analysis were done by using chi-square test wherever applicable. $P$ value $<0.05$ was taken as significant.

Statistical analysis is done by using XL Stat software.

\section{RESULTS}

In the present study of 120 patients 69 patients $(57.5 \%)$ were males and 51 (42.5\%) were females. Of them, 16 (23.19\%) males died and 13 (25.49\%) female patients died.

Results were analysed with XL Stat software. Results were expressed in mean +/_ standard deviation. $\mathrm{P}$ value $<0.05$ was taken as significant.

Glasgow coma scale is a significant predictor of mortality. It is inversely proportional to the mortality. There is $100 \%$ mortality in patients of GCS of 3, whereas mortality is $93.75 \%$ in patients with GCS of 6 and $93.57 \%$ in patients of GCS 7 .

$\mathrm{X}^{2}(\mathrm{X}$ square $)=21.34, \mathrm{p}=0.0001(\mathrm{p}<0.005$ significant $)$ 
In the present study, Glasgow coma score is a significant predictor of mortality. The score is inversely proportional to mortality, $\mathrm{p}<0.0001$.

\section{Age Distribution}

\begin{tabular}{|c|c|c|c|c|}
\hline Age Group & No. of Pts. & \% & No. of Pts. Dead & \% \\
\hline $12-20$ & 17 & 14.6 & 3 & 17.64 \\
\hline $21-30$ & 30 & 25 & 8 & 22.66 \\
\hline $31-40$ & 21 & 17.5 & 2 & 9.52 \\
\hline $41-50$ & 27 & 22.5 & 7 & 25.93 \\
\hline $51-60$ & 16 & 13.33 & 4 & 25 \\
\hline $61-70$ & 07 & 5.85 & 3 & 42.86 \\
\hline $71-80$ & 02 & 1.66 & 2 & 100 \\
\hline \multicolumn{7}{|c|}{ Table 1. Age distribution in the Present Study } \\
\hline
\end{tabular}

Age distribution in the present study was as shown in the above table. Coma was seen most commonly in 21 - 20 years' age group. Increased age is associated with increased mortality.

Aetiology of coma: In the present study, the aetiology of coma was found to be as follows.

\begin{tabular}{|c|c|c|c|c|c|}
\hline Aetiology & & $\begin{array}{c}\text { No. of } \\
\text { Patients }\end{array}$ & (\%) & \begin{tabular}{|c|} 
No. of \\
Patients \\
Dead
\end{tabular} & $\begin{array}{c}\text { Mortality } \\
\text { (\%) }\end{array}$ \\
\hline \multicolumn{6}{|c|}{ Toxic } \\
\hline & Poisoning & 9 & $7-5$ & 1 & 11.11 \\
\hline & $\begin{array}{c}\text { Alcohol } \\
\text { intoxication }\end{array}$ & 20 & 16.66 & 0 & 0 \\
\hline \multicolumn{6}{|c|}{ Infections } \\
\hline & $\begin{array}{l}\text { Cerebral } \\
\text { malaria }\end{array}$ & 34 & 28.33 & 8 & 23.5 \\
\hline & TB meningitis & 10 & 8.33 & 2 & 20 \\
\hline & Encephalitis & 2 & 1.66 & 1 & 50 \\
\hline \multicolumn{6}{|c|}{ Metabolic } \\
\hline & Hypoglycaemia & 2 & 1.66 & 0 & 0 \\
\hline & Hyponatraemia & 5 & 4.16 & 1 & 20 \\
\hline & DKA & 1 & 0.83 & 0 & 0 \\
\hline & $\begin{array}{c}\text { Hepatic } \\
\text { encephalopathy }\end{array}$ & 10 & 8.33 & 4 & 40 \\
\hline & $\begin{array}{c}\text { Uraemic } \\
\text { encephalopathy }\end{array}$ & 7 & 5.83 & 6 & 85.77 \\
\hline \multicolumn{6}{|c|}{ Miscellaneous } \\
\hline & \begin{tabular}{|c|} 
HTN \\
encephalopathy
\end{tabular} & 4 & 3.33 & 1 & 25 \\
\hline & Postictal coma & 8 & 6.66 & 0 & 0 \\
\hline & $\begin{array}{c}\text { Hypoxic } \\
\text { encephalopathy }\end{array}$ & 4 & 3.33 & 3 & 75 \\
\hline & $\begin{array}{c}\text { Septic } \\
\text { encephalopathy }\end{array}$ & 4 & 3.33 & 2 & 50 \\
\hline Total & & 120 & & 29 & \\
\hline
\end{tabular}

In the present study alcohol intoxication, cerebral malaria was found to be the commonest cause of coma with normal CT scan brain.

Mortality with respect to risk factors when mortality of the patients was analysed with respect to the risk factors results were as follows.

\begin{tabular}{|c|c|c|c|}
\hline Risk Factor & No. of Cases & $\begin{array}{c}\text { No. of Pts. } \\
\text { Dead }\end{array}$ & $\begin{array}{c}\text { Mortality } \\
\text { Percentage }\end{array}$ \\
\hline HTN & 20 & 6 & 30 \\
\hline Diabetes & 6 & 4 & 66.66 \\
\hline HTN + Diabetes & 15 & 6 & 40 \\
\hline Smoking & 30 & 9 & 18 \\
\hline Table 3. Mortality with respect to the Risk Factors in the \\
Present Study \\
\hline
\end{tabular}

When mortality in the present study was analysed with respect to Glasgow coma scale, the results were as follows:

\begin{tabular}{|c|c|c|c|c|}
\hline GCS Score & No. of Pts. & $\%$ & No. of Deaths & \% \\
\hline 3 & 1 & 0.83 & 1 & 100 \\
\hline 4 & 10 & 8.33 & 9 & 90 \\
\hline 5 & 21 & 17.5 & 14 & 66.66 \\
\hline 6 & 32 & 26.66 & 3 & 9.375 \\
\hline 7 & 56 & 46.66 & 2 & 3,57 \\
\hline Table 4. Glasgow Coma Scale at admission with respect to \\
Prognosis \\
\hline
\end{tabular}

Low Glasgow coma scale was associated with increased mortality, increasing drastically if the value is 5 or less.

When the duration of coma with respect to prognosis was analysed, the results were as follows:

\begin{tabular}{|c|c|c|c|c|}
\hline $\begin{array}{l}\text { No. of Days } \\
\text { in Coma }\end{array}$ & $\begin{array}{l}\text { No. of } \\
\text { Pts. }\end{array}$ & \begin{tabular}{|c|} 
No. of Pts. \\
Dead \\
\end{tabular} & \begin{tabular}{|l|} 
No. of Pts. \\
Recovered \\
\end{tabular} & Mortality \\
\hline 1 & 13 & 0 & 13 & 0 \\
\hline 2 & 22 & 0 & 22 & 0 \\
\hline 3 & 20 & 1 & 19 & 5 \\
\hline 4 & 15 & 4 & 11 & 26.66 \\
\hline 5 & 17 & 7 & 10 & 41.17 \\
\hline 6 & 11 & 4 & 7 & 36.36 \\
\hline 7 & 3 & 1 & 2 & 33.33 \\
\hline 8 & 8 & 5 & 3 & 62.5 \\
\hline 9 & 1 & 1 & 0 & 100 \\
\hline 10 & 5 & 3 & 2 & 60 \\
\hline 11 & 1 & 1 & 0 & 100 \\
\hline 12 & 2 & 1 & 1 & 50 \\
\hline 13 & 1 & 0 & 1 & 0 \\
\hline \multirow[t]{2}{*}{14} & 1 & 1 & 0 & 100 \\
\hline & 120 & 29 & 81 & \\
\hline
\end{tabular}

All patients with duration of coma less than 2 days, recovered completely. As the duration of coma increased, mortality raises.

Outcome: In the present study of 120 patients, 29 (24.6\%) patients died and 91 patients $(75.83 \%)$ recovered. Among the recovered patients 83 (91.2\%) patients had good functional recovery, 7 (7.69\%) patients were left with moderate disability and $1(1.09 \%)$ patient was left with severe disability.

\section{DISCUSSION}

In the present study of 120 patients with coma with normal CT scan brain, most of the patients were in 3 rd decade $25 \%$. Male preponderance was observed in $57.5 \%$ compared to females $42.5 \%$. In the present study the aetiology of coma with normal CT scan brain, infectious aetiology, metabolic causes and toxic causes accounted for $38.33 \%, 37.5 \%$ and $24.16 \%$ respectively. In the study by Plum and Posner et al (1981), toxic and metabolic causes were found to be more 
common $45.7 \%$ and $42.38 \%$ respectively and infections accounted for $4.29 \%$. In the study by Grmec et al (2001), toxic causes were found to be the commonest in $44.8 \%$ and metabolic and infectious causes accounted for $20.51 \%$ and $20.51 \%$ in each respectively.

Infections and metabolic causes were similarly reported in both sexes. Cerebral malaria was the commonest cause of coma in $31.66 \%$ followed by alcohol intoxication in $16.66 \%$. Mortality is about $23-25 \%$, similar in both sexes. As the patient's age increased, raise in the mortality was noted. Mortality was highest in 71 - 80 years' patient group, similar to the study by Grmec et al in 2001 where the patients who died were older than who survived $(66.8 \pm 11.1$ years versus $46.1 \pm 15.4$ years, $\mathrm{p}<0.005)^{6}$

Highest mortality is seen in metabolic coma and lowest mortality was seen in coma due to toxic causes. Of metabolic coma uraemic encephalopathy is associated with highest mortality, $85.77 \%$ followed by hypoxic encephalopathy and $75 \%$. In coma secondary to alcohol intoxication, diabetes ketoacidosis, hypoglycaemia and postictal coma, all patients survived.

Diabetic patients have $66.6 \%$ mortality and hypertensive patients $40 \%$ mortality.

Glasgow coma scale was a significant predictor of mortality with an inverse relation $(\mathrm{p}<0.0001)$. In our study we found that in patients with less Glasgow coma scale 7 , mortality was seen in $3.75 \%$, whereas mortality raised steeply if the Glasgow coma scale is 5 or less. Similar findings were observed in other studies.

The duration of coma was also found to be associated with prognosis. In patients with coma of less than 2 days duration, all patients survived. As the duration of coma increased, rise in mortality was noted.

In our study overall mortality noted was $24.16 \%$, is much less when compared to other studies. The reason might be because the studies were done earlier as more sophisticated investigations and effective treatments are available now. Cerebral malaria and alcohol intoxication were seen in majority of our cases, which are potentially treatable.

\begin{tabular}{|c|c|c|c|c|c|}
\hline Outcome & $\begin{array}{c}\text { Plum } \\
\text { and } \\
\text { Posner } \\
\text { et al }\end{array}$ & $\begin{array}{c}\text { Levy } \\
\text { et al }\end{array}$ & $\begin{array}{c}\text { Sharma } \\
\text { et al7 }\end{array}$ & $\begin{array}{c}\text { Thacker } \\
\text { et al8 }\end{array}$ & $\begin{array}{c}\text { Present } \\
\text { Study }\end{array}$ \\
\hline Death & $61 \%$ & $61 \%$ & $80 \%$ & $50 \%$ & $24.16 \%$ \\
\hline Recovery & $39 \%$ & $39 \%$ & $20 \%$ & $50 \%$ & $75.83 \%$ \\
\hline Table 6. Overall Mortality in Comparison with Other \\
Studies \\
\hline
\end{tabular}

\section{CONCLUSION}

In patients of coma with normal CT scan brain, male $(57.51 \%)$ preponderance was noted. Metabolic causes (37.5\%) and infections (38.3\%) accounted for about $75 \%$ of all cases of coma with normal CT brain in the present study. Cerebral malaria (31.66\%) accounted for majority of infectious causes. Highest mortality is seen in metabolic coma (37.78\%), of which uraemic encephalopathy $(85.77 \%)$ accounted for majority of the cases. Glasgow coma scale at admission and duration of coma are good predictors of prognosis and outcome.

\section{REFERENCES}

[1] Plum F, Posner JB. Pathophysiology of signs and symptoms of coma. In: Gilman S, Posner JB, Saper CB, et al. eds. Plum and Posner's Diagnosis of stupor and coma. $4^{\text {th }}$ edn. Oxford University Press 2007: p. 3-37.

[2] Giacino JT, Ashwal S, Childs N, et al. The minimally conscious state: definition and diagnostic criteria. Neurology 2002;58(3):349-53.

[3] Levy DE, Bates D, Caronna JJ, et al. Prognosis in nontraumatic coma. Ann Internal Medicine 1981;94(3):293-301.

[4] Teasdale G, Jennett B. Assessment of coma and impaired consciousness: a practical scale. Lancet 1974;2(7872):81-4.

[5] Washburn, Leslie A. Altered mental status: causes, determinants and treatment. Journal of the American Academy of Physician Assistants 2005;18(2):16-22.

[6] Grmec S, Gasparovic V. Comparison of APACHE II, MEES and Glasgow Coma scale in patients with nontraumatic coma for prediction of mortality. Critical Care 2001;5(1):19-23.

[7] Sharma S, Gupta S, Gupta SR. Prognosis in nontraumatic coma. Neurology India 1995;43(4):199-201.

[8] Thacker AK, Singh BN, Sarkari NB, et al. Non-traumatic coma-profile and prognosis. JAPI 1997;45(4):267-70. 